\title{
Emotional Intelligence and Adjustment of Sports persons
}

\author{
Dharmendra Pratap Singh ${ }^{1}$, Dr. B. K. Bhardwaj ${ }^{2}$
}

\section{ABSTRACT}

The demand for adjustment is universal to all human beings and characterized by uniqueness, dynamicity, pervasiveness and indispensability. The processes and mechanisms of adjustment entail factors associated with the personal attributes of the individuals, socio-cultural milieu and genetic endowment which determine its exact nature, extent and quality. The sports relationship is unique and places a different type of demand on the part of sportspersons. Out of many stake holders of adjustment in the field of sports and games, the emotions play a pivotal role. The present research attempted to spell out the impact of emotional intelligence and gender in shaping the adjustment of the sportspersons. The study employed four hundred sportspersons with equal number of males and females as participants whose emotional intelligence and adjustment were measured through standardized psychometric tools. The results evinced that male and female differed in their four components and overall mean scores of emotional intelligence. The female participants evinced higher mean emotional intelligence score as compared to their male counterparts as well as on intrapersonal awareness and intrapersonal management dimensions of emotional intelligence. Contrarily, there were no gender differences on interpersonal awareness and interpersonal management dimensions emotional intelligence. In addition, the scores of emotional intelligence showed statistically significant positive correlations with all the four areas of adjustment such as home adjustment, health adjustment, social adjustment and emotional. The results have been discussed in the light of current theories of emotional intelligence and adjustment. The conclusions of the study have important theoretical and practical implications for the academicians, administrators, sportspersons, researchers of other professional associated with sports field and policy maker.

Keywords: Emotional Intelligence, Adjustment, Gender, Sportsperson, Game type.

The sportspersons have to face many challenges and demands imposed on them encompassing personal, social, emotional, and familial as well as health-related. The role of various emotions

\footnotetext{
${ }^{1}$ Research Scholar, Department of Physical Education, Mewar University, NH-79, Gangrar, Chittorgarh, 312 901, Rajasthan India

${ }^{2}$ Associate Professor, Department of Physical Education, Baiswara P. G. College, Lalganj, Raebereli, U. P. India *Responding Author

(C) 2016 I D Singh, B Bhardwaj; licensee IJIP. This is an Open Access Research distributed under the terms of the Creative Commons Attribution License (http://creativecommons.org/licenses/by/2.0), which permits unrestricted use, distribution, and reproduction in any Medium, provided the original work is properly cited.
} 


\section{Emotional Intelligence and Adjustment of Sports persons}

such as anxiety, anger along with other emotions in sports performance and adjustment is very crucial. The research findings encompassing regulatory role of emotional intelligence for sports performance and concomitant adjustment is important and exciting. It is argued that recognition of various emotions and emotional states, assessments of their impacts on the various aspects of the sportspersons behaviours, performance and management of others as well as ones emotions are crucial for success and adjustment in the area of sports and games. Thus, the importance and unavoidable role of positive and negative emotions, the recognition, understanding, managing emotions, the regulation of emotions in the context of professional, personal and social spheres of life of sportspersons are being recognized by the scientists, academicians, administrators, policy makers and managers and coaches of all sports activities and organizations. This not to argue here that only emotional intelligence affects and determines the way people behave and perform in many situations. Physical challenges and serious illness like HIV-AIDS seriously affect the various performance indices by affecting emotion regulation processes (Tiwari, 2015; Tiwari, \& Kumar, 2014), self-forgiveness processes (Mudgal \& Tiwari, 2015) and body image satisfaction (Jain \& Tiwari, 2016) and vice versa (Tiwari, 2014) which, in turn, actually shape and regulate the quality of performance and functioning of the individuals. The achievement and performance in academic and other areas might also be determined, to a large extent, by the nature and dynamics of self-concept and self-esteem (Tiwari, 2011) and these have significant associations with emotional intelligence.

The emotional intelligence refers to the ability to recognize and regulate emotions in oneself and others (Goleman, 2001) and it has been found to be significantly associated with the performance of various areas such as social behaviour (Mavroveli, Petrides, Rieffe, \& Bakker, 2007), adaptive coping and depressive affect (Mavroveli, Petrides, Rieffe, \& Bakker, 2007), leadership (Villanueva \& Sanchez, 2007), happiness (Chamorro-Premuzic, Bennet, \& Furnham, 2007), emotion regulation (Mikolajczak, Nelis, Hansenne, \& Quoidbach, 2008), affective decisionmaking (Sevdalis, Petrides, \& Harvey, 2007) and various kind of performance (Petrides, Pita, \& Kokkinaki, 2007). In addition, it is also associated with adaptive psychological functioning (Kirk, Schutte, \& Hine, 2008) and adaptive social functioning, and interpersonal communication (Denham, 1998; Izard, 2001).

A growing interest in emotional intelligence in sport proves (Lane, Thelwell, \& Devonport, 2009) that different emotions are related with successful performance (vigour, happiness, and calmness), poor performance (confusion, depression and fatigue) and correlated with frequent use of psychological skills (Lane, Thelwell, Lowther, \& Devonport, 2009). A large number of evidence supports the notion that variations in emotional intelligence relate to variations in sport performance (Beedie, Terry, \& Lane, 2000; Robazza, Pellizzari, Bertollo, \& Hanin, 2008). The athletes demonstrating high emotional intelligence also showed frequent use of psychological skills (Thomas, Murphy, \& Hardy, 1999). The results of meta-analyses studies demonstrated that successful performance is associated with higher scores of vigour and lower scores of anger, 


\section{Emotional Intelligence and Adjustment of Sports persons}

confusion, depression, fatigue and tension (Beedie, Terry, \& Lane, 2000). However, the results of meta-analysis show inconsistent emotion-performance relationships for anger and tension. Anger and/or tension positively correlate with performance in some studies and negatively correlate with performance in others (Beedie et al., 2000).

Researchers have found emotional quotient possessing high predictive capability of performance and adjustment in various areas. A significant positive correlation between emotional quotient (EQ) and social adjustment was observed in India also (Dhingra, Manhas \& Thakur, 2005; Rathee, 2009; Suri, 2008). Similarly, Chen, Lin \& Tu (2006) reported a positive correlation between emotional intelligence and life adjustment (personal adjustment, family adjustment, peer adjustment and school adjustment) of senior high school students in Taiwan and Anhui province in mainland China. Rathee (2009) also reported the same findings in his study of emotional intelligence and adjustment among one hundred female college students comprising equal number of sports and non-sports persons. The demographic attributes of the individuals such age, gender and socioeconomic status etc. have mediating role in one's adjustment. Noor-Azniza, Malek, Saleh, Farid, (2011) studied impact of emotional intelligence, gender and age on social and academic adjustment and found no significant relationship between emotional intelligence social and academic adjustments.

The above reviews of the previous work make it explicit that the role of emotional intelligence in almost all walks of life is very clear, evident and amazing. It was also observed that the impacts of emotional intelligence is not direct and it is mediated by a host of factors associated with the individual's personal, social, familial, cultural, occupational as well as biographic factors. The review made it evident that there is dearth of studies, sometimes contradictory, pursuing the impacts of emotional intelligence in determining the degree of adjustment of sportspersons and mediating role of gender. Thus, the present study aimed to explicate the impacts of emotional intelligence and gender on the adjustment of sportspersons. The major objectives of the present study were: 1 . to understand the dynamics of the impacts of emotional intelligence on the adjustment of sportspersons; 2. to find out gender differences in emotional intelligence sportspersons, and 3. to find out the gender differences in adjustment of sportspersons.

\section{METHODS AND PROCEDURE}

\section{Participants}

Four hundred (200 males and 200 female) sportspersons of different Degree Colleges affiliated to Dr. Ram Manohar Lohia Avadh University, Faizabad, Uttar Pradesh, India, playing at intercollegiate level in various games age ranging from 18 to 25 selected by stratified random sampling technique belonging to different games participated in the present study. Team games were football, hockey, basketball, volleyball and cricket, while the individual games were badminton, athletics, table tennis, wrestling and chess. 


\section{Emotional Intelligence and Adjustment of Sports persons}

\section{Tools}

Following tools were employed for the measurement of emotional intelligence and adjustment of the participants of the present study:

\section{(a.) Emotional Intelligence Inventory}

It has been designed and standardized by Mangal and Mangal (2004) for the measurement of emotional intelligence (total as well as in its four separate components) in respect of four areas or aspects of emotional intelligence namely, intrapersonal awareness (knowing about one's own emotions), interpersonal awareness (knowing about other's emotions), intrapersonal management (managing one's own emotions) and interpersonal management (managing other's emotions), respectively. A higher score of the individual in the respective areas, as well as total, shows a higher level of emotional intelligence and lower score a lower level of emotional intelligence.

\section{(b.) Bell's Adjustment Inventory}

Indian Adaptation of Bell's Adjustment Inventory by Ojha (1996) consisting 140 items pertaining to the areas of human health, social and emotional was used to measure the adjustment of the participants. It has been reported to have the acceptable psychometric properties and gained popularity among the researchers around the globe.

\section{Procedure}

The participants were consulted personally and debriefed about the basic objectives and expectations of the study. The participants filled in the consent form before they actually started responding against the various items the scales. All the sportsmen/women are required to complete the scales to assess their emotional intelligence and adjustment of male and female sportspersons. The final data treated with the mean, SDs and F-ratio statistics.

\section{RESULTS}

The results of the present study indicated that the female participants evoked higher mean score on intrapersonal awareness $(\mathrm{M}=17.50, \mathrm{SD}=2.95)$, intrapersonal management $(\mathrm{M}=17.30, \mathrm{SD}=$ 2.24) and overall emotional intelligence $(M=67.40, S D=7.20)$ dimension of emotional intelligence as compared to the male participants who scored $(\mathrm{M}=16.80, \mathrm{SD}=2.64),(\mathrm{M}=$ $16.00, \mathrm{SD}=1.90)$ and $(\mathrm{M}=65.40, \mathrm{SD}=7.53)$, respectively, on the same dimensions. On the rest measures of emotional intelligence, the male participants achieved similar mean scores on interpersonal awareness $(\mathrm{M}=16.50, \mathrm{SD}=1.97)$ and interpersonal management $(\mathrm{M}=16.10$, SD $=1.70)$ dimensions of emotional intelligence as to those with the females $(\mathrm{M}=16.50, \mathrm{SD}=1.75)$ and $(\mathrm{M}=16.10, \mathrm{SD}=1.30)$ participants, respectively (Table 1$)$.

Thus, it is clear that the gender differences existed in emotional intelligence on some dimensions whereas on the other the gender difference did not surface. The F-ratio demonstrated that females scored relatively higher intrapersonal awareness $(\mathrm{M}=17.50, \mathrm{SD}=2.95)$ in comparison to males $(\mathrm{M}=16.80, \mathrm{SD}=2.64)$. The main effect of gender on intrapersonal awareness, $F$ $(1,396)=7.092, p=.008$, was also found to be statistically significant. 
Emotional Intelligence and Adjustment of Sports persons

Table 1: Pattern of emotional intelligence across game type and gender

\begin{tabular}{|c|c|c|c|}
\hline Game Type & \multicolumn{3}{|c|}{ Total } \\
\hline Gender & Male (N=200) & Female (N=200) & Total (N=400) \\
\hline Emotional Intelligence & $\mathrm{M}(\sigma)$ & $\mathrm{M}(\sigma)$ & $\mathrm{M}(\sigma)$ \\
\hline Intrapersonal Awareness & $16.80(2.64)$ & $17.50(2.95)$ & $17.15(2.82)$ \\
\hline Interpersonal Awareness & $16.50(1.97)$ & $16.50(1.75)$ & $16.50(1.86)$ \\
\hline Intrapersonal Management & $16.00(1.90)$ & $17.30(2.24)$ & $16.65(2.18)$ \\
\hline Interpersonal Management & $16.10(1.70)$ & $16.10(1.30)$ & $16.10(1.51)$ \\
\hline Emotional Intelligence & $65.40(7.53)$ & $67.40(7.20)$ & $66.40(7.43)$ \\
\hline
\end{tabular}

Pearson's coefficient of correlations was computed to find out the nature of relationship among emotional intelligence, and adjustment the sportspersons. A perusal of Table 2 demonstrate that various components of emotional intelligence showed significant positive correlations with all the four areas of adjustment home adjustment $(r=.608, p<0.01)$, health adjustment $(r=.566, p$ $<0.01)$, social adjustment $(r=.548, p<0.01)$ and emotional adjustment $(r=.908, p<0.01)$.

Table 2: Correlations among the scores of Emotional Intelligence and Adjustment of the sportspersons

\begin{tabular}{|c|l|c|c|c|c|c|c|c|c|}
\hline $\begin{array}{c}\text { S. } \\
\text { No. }\end{array}$ & \multicolumn{1}{|c|}{ Variables } & $\mathbf{1 .}$ & $\mathbf{2 .}$ & 3. & $\mathbf{4 .}$ & $\mathbf{5 .}$ & $\mathbf{6 .}$ & $\mathbf{7 .}$ & $\mathbf{8 .}$ \\
\hline 1. & $\begin{array}{l}\text { Intrapersonal } \\
\text { Awareness }\end{array}$ & 1 & $.674^{* *}$ & $.923^{* *}$ & $.571^{* *}$ & $.608^{* *}$ & $.566^{* *}$ & $.548^{* *}$ & $.908^{* *}$ \\
\hline 2. & $\begin{array}{l}\text { Interpersonal } \\
\text { Awareness }\end{array}$ & 1 & $.613^{* *}$ & $.836^{* *}$ & $.483^{* *}$ & $.614^{* *}$ & $.791^{* *}$ & $.794^{* *}$ \\
\hline 3. & $\begin{array}{l}\text { Intrapersonal } \\
\text { Management }\end{array}$ & & 1 & $.573^{* *}$ & $.702^{* *}$ & $.413^{* *}$ & $.563^{* *}$ & $.877^{* *}$ \\
\hline 4. & $\begin{array}{l}\text { Interpersonal } \\
\text { Management }\end{array}$ & & & 1 & $.609^{* *}$ & $.618^{* *}$ & $.967^{* *}$ & $.784^{* *}$ \\
\hline 5. & Home Adjustment & & & & & 1 & $.178^{* *}$ & $.571^{* *}$ & $.690^{* *}$ \\
\hline 6. & Health Adjustment & & & & & & 1 & $.515^{* *}$ & $.600^{* *}$ \\
\hline 7. & Social Adjustment & & & & & & & 1 & $.773^{* *}$ \\
\hline 8. & Emotional Adjustment & & & & & & & & 1 \\
\hline
\end{tabular}

$* * p<.05$

\section{DISCUSSION}

The results of the study made it clear that emotional intelligence has very crucial for the determining the nature and extent of levels of adjustment of the sportspersons along with gender. These two factors significantly shaped the adjustment of the adjustment of the participants. The results evinced that the female participants accumulated higher mean score on intrapersonal awareness, intrapersonal management and overall emotional intelligence dimension of emotional intelligence as to those of male participants, while on the rest of the dimensions both the group of

(c) The International Journal of Indian Psychology, ISSN 2348-5396 (e)| ISSN: 2349-3429 (p) | 90 


\section{Emotional Intelligence and Adjustment of Sports persons}

participants achieved similar mean scores. It pointed out towards a reality that the gender differences existed in emotional intelligence make up of males and females. The findings were also approved by the computational the F-ratios.

The coefficient of correlations indicated that various components of emotional intelligence showed significant positive correlations with all the four areas of adjustment home adjustment, health adjustment, social adjustment and emotional adjustment. Recent research by Hanin and Stambulova (2002) has identified the importance in distinguishing a specific set of emotion content that is optimal or dysfunctional for an athlete's performance. The research has suggested that due to the dynamic nature of emotional content that it would be useful to isolate temporal patterns of emotions throughout a particular competition or several competitions so as to plan psychological interventions and strategies for performance improvement (Hanin \& Stambulova, 2002).

Based on Hanin's model, it has been proposed that the function of emotions in the sporting arena be studied through five basic dimensions; form, content, intensity, time and context (Crust, 2002). Acknowledging that a wide range of emotions, other than anxiety, characterize sporting experience, Hanin's model (2000) suggests that a range of positive and negative emotions can both facilitate, as well as inhibit, performance. The model suggests that positive and negative emotions may exert beneficial or detrimental effects depending on their idiosyncratic meaning and intensity.

The present study was marred by some limitations too. Small sample, stratified sampling, small number of predictor variables and single area of data were some of the important limitations of the present study. Future researchers may involve larger sample with diversified geographical areas and a good number of predictors. It is also recommended that along with quantitative methods, qualitative as well mixed methods may be employed by future researchers to spell out the exact role played by emotional intelligence and consonant mediating variables in determining the adjustment and well-being of the individuals not only in the area of sports and games but also in other important spheres of human functioning and activity.

\section{Acknowledgments}

The author appreciates all those who participated in the study and helped to facilitate the research process.

\section{Conflict of Interests}

The author declared no conflict of interests. 


\section{REFERENCES}

Beedie, C. J., Terry, P. C., \& Lane, A. M. (2000). The Profile of Mood States and Athletic Performance: Two meta-analyses. Journal of Applied Sport Psychology, 12, 49-68.

Chamorro-Premuzic, T., Bennett, E., \& Furnham, A. (2007). The happy personality: Mediational role of trait emotional intelligence. Personality and Individual Differences, 42, 1633-1639.

Chen, F.S., Lin, Y.M. and Tu, C.A. (2006). A study of the emotional intelligence and life adjustment of senior high school students. World Transactions on Engineering and Technology Educ., 5, 3, 473-476

Crust, L. (2002). Emotional Control: These pre-performance strategies will take control of your emotions before they take control of you. Peak performance, 172, 1-4.

Denham, S. A. (1998). Emotional development in young children. New York: The Guilford Press.

Dhingra, R., Manhas, S., \& Thakur, N. (2005). Estabilishing Connectivity of Emotional Quotient (E.Q), Spiritual Quotient with Social Adjustment: A Study of Kashmiri Migrant Woman. J. Hum. Ecol. 18(4), 313-317.

Goleman, D. (2001). Emotional intelligence: Issues in paradigm building. In C. Cherniss \& D. Goleman (Eds.), The emotionally intelligent workplace. San Francisco: Jossey-Bass.

Hanin Y. L., \& Stambulova, N. B. (2002). Metaphoric description of performance states: An application of the IZOF model. The Sport Psychologist 16, 396-415.

Izard, C. E. (2001). Emotional intelligence or adaptive emotions? Emotion, 1, 249-257.

Jain, P., \& Tiwari, G. K. (2016). Body image satisfaction and Life Satisfaction in HIV/AIDS patients. The International Journal of Indian Psychology, Volume 3, Issue 2, No.1, 81-90. DIP: 18.01.011/20160302.

Kirk, B. A., Schutte, N., \& Hine, D. W. (2008). Development and preliminary validation of an emotional intelligence efficacy scale. Personality and Individual Differences, 45, 432-436.

Lane, A. M., Thelwell, R., \& Devonport, T. J. (2009). Emotional intelligence and mood states associated with optimal performance. Electronic Journal of Applied Psychology: General Articles, 5, 67-73.

Lane, A. M., Thelwell, R., Lowther, J. P., \& Devonport, T. J. (2009). Emotional intelligence and psychological skills use among athletes. Social Behaviour and Personality: An International Journal, 37, 195-201.

Mangal, S. K., \& Mangal, S. (2004). Manual for Mangal Emotional Intelligence Inventory. Agra: National Psychological Corporation.

Mavroveli, S. Petrides. K. V., Rieffe, C., \& Bakker, F. (2007). Trait emotional intelligence, psychological well-being, and peer-ratedsocial competence in adolescence. British Journal of Developmental Psychology, 25, 263-275.

Mikolajczak, M., Nelis, D., Hansenne, M., \& Quoidbach, J. (2008). If you can regulate sadness, you can probably regulate shame: associations between trait emotional intelligence, emotion regulation and coping efficiency across discrete emotions. Personality and Individual Differences, 44, 1356-1368. 


\section{Emotional Intelligence and Adjustment of Sports persons}

Mudgal, S., \& Tiwari, G. K. (2015). Self-Forgiveness and Life Satisfaction in People Living with HIV/AIDS. The International Journal of Indian Psychology, Volume 3, Issue 1, No.10, 101-108. DIP: C03175V3I12015.

Noor-Azniza, I., Malek, T. J., Saleh, I. Y., \& Farid, T. M. (2011). Moderating Effect of Gender and Age on the Relationship between Emotional Intelligence with Social and Academic Adjustment among First Year University Students. Int. J. Psychol. Studies, 3(1), 78-89.

Ojha, R.K. (1996). Bell's adjustment inventory. National Psychological Corporation, Agra. Uttar Pradesh, India

Petrides, K. V., Pita, R., \& Kokkinaki, F. (2007). The location of trait emotional intelligence in personality factor space. British Journal of Psychology, 98, 273-289.

Rathee, N. K. (2009) Investigation of social Psychological differentials among college student Psycho-lingua, 39, $134-38$

Robazza, C., Pellizzari, M., Bertollo, M., \& Hanin, Y. L. (2008). Func-tional impact of emotions on athletic performance: Comparing the IZOF model and the directional perception approach. Journal of Sports Sciences, 26, 1033-1047.

Sevdalis, N., Petrides, K. V., \& Harvey, N. (2007). Trait emotional intelligence and decisionrelated emotions. Personality and Individual Differences, 42, 1347-1358.

Suri, R. (2008) Impact of emotional intelligence in adjustment of XII Class Students. Paper presented at national Seminar on Psychology for better life (12th \& 13th September 2008) Deptt. Of Psychology, Arts and Commerce College, Raipur (C.G.)

Thomas, P. R., Murphy, S., \& Hardy, L. (1999). Test of Performance Strategies: Development and preliminary validation of a comprehensive measure of athletes' psychological skills. Journal of Sports Sciences, 17, 697-711.

Tiwari, G. K. (2011). Academic self-esteem, feedback and adolescents’ academic achievement. Anusilana, XXXVII, 15-22.

Tiwari, G. K. (2014). Body image satisfaction enhances self-esteem. VAICHARIKI, IV (4), 7-11.

Tiwari, G. K. (2015). Chronic Physical Illness Affects Emotion Regulation Process: A Case of HIV/AIDS. The International Journal of Indian Psychology, Volume 3, Issue 1, No.8, 158-166. DIP: C03143V3I12015.

Tiwari, G. K., \& Kumar. S. (2014). Psychology of body image: A review. SHODH PRERAK, 5 (1), 1-9.

Villanueva, J. J., \& Sanchez, J. C. (2007). Trait emotional intelligence and leadership selfefficacy: Their relationship with collective efficacy. Spanish Journal of Psychology, 10, 349-357.

How to cite this article: D Singh, B Bhardwaj (2016), Emotional Intelligence and Adjustment of Sports persons, International Journal of Indian Psychology, Volume 3, Issue 4, No. 59, ISSN 2348-5396 (e), ISSN: 2349-3429 (p), DIP: 18.01.066/20160304, ISBN: 978-1-365-26307-1 